\title{
Valuing Rider Quality in Swedish Special Transport Services-New Findings
}

Stig Knutsson, Department of Social Work, Stockholm University

\section{Abstract}

The Swedish Special Transport Services, with 0.42 million authorized pass-holders, is integrated into the Swedish public transport system. This article compares STS rider quality with present-day public transportation standards.

A Swedish rider quality index is used to examine a stated preference questionnaire sent to 2,200 randomly chosen riders in Stockholm, Göteborg, and one rural district. A logit model was used for the statistical analysis.

Waiting time at telephone switchboard was weighed for the entire population to 81 percent, information to 53 percent, and driver assistance to 21 percent regarding trip frequency. One minute Waiting time at telephone switchboard corresponed to 17.5 minutes travel time in the vehicle. Several rider catagories ar e discussed.

The resultsof this analysis help to bring into focus decisive quality development aspects of the regular public transportation system from a city perspective. This is important, especially in encouraging the elderly, who experience different kinds of functinal disabilities, to use the regular public transportation system more often than they do at the present time. A public transportation stand ard must be offered that is adequate and that corresponds in quality to what both employed and elderly disabled riders want and need in accordance with their capabilities. Questions 
concerning timetable, information, and driver assistance are brought forward as important attraction components.

\section{Introduction}

The main Special Transport Services (STS) travel mode in Sweden is "färdtjänst." The färdtjänst mode is comprised of 400,200 STS pass-holders. In 2001 the STS provided $13,556,100$ one-way trips (SIKA 2002). In 2000, Stockho Im County alone had 20.8 percent of all the riders in Sweden and 25.6 percent of all one-way trips in the country (SIKA 2002). Taxicabs and minivans are used for the trips and authority-organized vehicle pooling is the basic passenger quality st andard. The most typical STS pass-holder in Sweden is a woman with pension benefits (National Board of Health and Welfare 1998); the most frequent user is, in contrast, an employed man around 40 years old.

A political policy shift, supported by the Swedish Special Transport Service Act 1997 (SFS 1997:736), has taken place within STS from the social policy area to the transport domicile. As a consequence, since 1998 STS has been seen as an integrated part of the public transport system in Sweden. The quality standard of this mode must be compared with the standard of the present public transport as opposed to the common interpretation of the Swedish legislation (SFS 1997:734, SFS 1997:736). The STS reformation is the result of a strongly expressed demand for Swedish transportation policy effectiveness in terms of government cost reduction (SFS 1997:736). Actual use of STS has also been dramatically reduced during the last decade. For example, in 1994 there were 441,300 STS pass-holders and the service provided $17,456.100$ one-way trips (SIKA 2002).

Performance evaluation methods are useful elements in the trans portation development process at least as far back as Paaswell (1977). We have frequently seen economical measurements of transport productivity from the producer perspective (Gillingwater et al. 1995; Thatcher et al. 1991). In Swede $n$, while it has also been common to measure STS productivity from the producer perspective in terms of quantity ahead of quality (Knutsson 1999), some attention has been given to rider quality aspects and attributes. In the United Kingdom, Sutton (1990) uses a multinominal logit model to estimate travel demand for STS. McKnight et al. (1986) provides a rider quality index for the United States. Mc Kee (1993) offers an outline of a rider quality model that focuses on rail vehicles accessible to disabled passengers. In a Swedish context, there is only one published report known (Knutsson 1998) to model STS travel demand in terms of rider qu ality attributes. 
This article reports on part of the 2000 follow-up study in the County of Stockholm, County of Östergötland, and the Municipality of Göteborg. It is based on results and knowledge from the reported 1998 Swedish study (Knutsson 1998).

\section{Methods}

A rider quality index of Swedish STS (Knutsson 1998, 2000) is u sed as a platform for the planned Stated Preference (SP) experiments. The Index of Rider Quality (IRQ) outlines the most important aspects of rider quality in a Swedish context based on customer utility and well-being in terms of the right to make choices, to act independently, and to maintain dignity and self-esteem.

For many years the SP technique, which normally deals with the demand of the average passenger, has been a common tool used in transportation research (Jones 1989; Pearmain et al. 1991; Widlert 1992). The SP should be designed with instinctive feeling toward the target rider group. But are the planned SP experiments a good, realistic, and beneficial strategy in this particular cas e? Based on the results of a customer postal questionnaire, the answer has to be yes.

The 2,200 receivers of the survey questionnaire, all with at le ast one STS trip in 1999, were randomly picked from the STS pass-holder population in the County of Stockholm, County of Östergötland, and the Municipality of G öteborg. The response frequency was 69 percent.

Chosen key attributes were based on the fact that STS quality s tandards have to be compared with passenger comfort in conventional public transport. The second reason for the choice was the desire to continue to expand the method approach from 1998 and to capture the most important attributes that depict no timerelated attributes. For the STS pass-holders, those attributes are closely linked to the ability to actually control the timetable of the trip. A crucial point is the authority-organized vehicle pooling and its effects on the rider's space of action.

The parameters used in this study included:

Information access (vehicle-pooling)

- Driver assistance

- Frequency of service

- In-vehicle time

- Waiting time at telephone switchboard 


\title{
Index of Rider Quality (IRQ) of STS
}

\author{
Source: Knutsson 1998
}

\begin{tabular}{|c|c|}
\hline Attribute & Measurement \\
\hline Information & $\begin{array}{l}\text { Information access } \\
\text { Understandable information } \\
\text { Faultless and complete information } \\
\text { Unambiguous information }\end{array}$ \\
\hline Dignity & $\begin{array}{l}\text { Being taken seriously as a traveller } \\
\text { Confidence with respect to what to do and where to go } \\
\text { Personal privacy } \\
\text { Reliability of service } \\
\text { Day and night time safety } \\
\text { Medical emergency capability } \\
\text { Suitability and motivation of driver } \\
\text { Courtesy and friendliness } \\
\text { Familiarity with personal needs }\end{array}$ \\
\hline Comfort & $\begin{array}{l}\text { Service on weekdays } \\
\text { Service on weekends } \\
\text { Punctuality of departure } \\
\text { Punctuality of arrival } \\
\text { Freedom from crowding } \\
\text { Booking } \\
\text { Follow-up to complaints } \\
\text { Few travel restrictions } \\
\text { Prebooking of return } \\
\text { Smoothness of ride } \\
\text { Vehicle inside design } \\
\text { Number of steps } \\
\text { Space and seating } \\
\text { Lift or ramp } \\
\text { Distance to vehicle } \\
\text { Driver assistance } \\
\text { Ease of complaining } \\
\text { Possibility to choose departure time }\end{array}$ \\
\hline Travel time & $\begin{array}{l}\text { Reasonable in-vehicle time } \\
\text { Waiting time away from home } \\
\text { Switchboard waiting time } \\
\text { Total trip time } \\
\text { Delays on vehicle } \\
\text { Prebooking time } \\
\text { Punctuality of pick-up time }\end{array}$ \\
\hline Fare & $\begin{array}{l}\text { Worth its price compared to public transport } \\
\text { Fare }\end{array}$ \\
\hline
\end{tabular}


The set of variables and their levels are detailed in Table 1. In relation to the IRQ index attributes, the IRQ attribute 31 opportunity to choose departure time is transformed to frequency of service in this study. Also, the IRQ attribute 32 reasonable in-vehicle time is shortened to in-vehicle time. In add ition, in-vehicle time in comparison with normal public transport minus 20 minutes in level A, represents an improvement and level B plus 10 minutes stands for a deterioration.

The results of this study are dependent on the SP design. There fore, the selected levels of the attributes are very important.

\section{Table 1. Variables and Levels Used in the Calculations}

\begin{tabular}{|c|c|c|c|c|c|c|}
\hline No & $\begin{array}{l}\text { Group of } \\
\text { Attribute }\end{array}$ & Variable & LevelA & Level B & LevelC & LevelD \\
\hline 1 & Information & $\begin{array}{l}\text { Information access } \\
\text { (vehicle-pooling) }\end{array}$ & No & Yes & & \\
\hline 29 & Comfort & Driver assistance & $\begin{array}{l}\text { All help } \\
\text { you need }\end{array}$ & As today & & \\
\hline 31 & Comfort & Frequency of service & Every $30 \mathrm{~min}$. & Yes & & \\
\hline 32 & Travel time & In-vehicle time & Minus $20 \mathrm{~min}$. & $+10 \mathrm{~min}$ & Equal & $-10 \mathrm{~min}$. \\
\hline 34 & Travel time & $\begin{array}{l}\text { Waiting time at } \\
\text { telephone switchboard }\end{array}$ & 0 minutes & 5 minutes & & \\
\hline
\end{tabular}

Rider attitudes toward authority-organized vehicle pooling, the basic STS performing standard today, is discussed later in this article. This rider quality aspect is not an independent attribute in the IRQ index. Instead, vehicle pooling has become an integrated part of the STS production form. Vehicle pooling consists of a large number of IRQ attributes (see Table 2). 


\section{Table 2. IRQ Variables Constituting the Authority-Organized Vehicle Pooling}

\begin{tabular}{lll}
\hline No & $\begin{array}{l}\text { Group of } \\
\text { Attribute }\end{array}$ & Variable \\
\hline 1 & Information & Information access (vehicle-pooling) \\
6 & Dignity & Confidence with respect to what to do and where to go \\
14 & Comfort & Service on weekdays \\
15 & Comfort & Service at weekends \\
16 & Comfort & Punctuality, departure \\
17 & Comfort & Punctuality, arrival \\
18 & Comfort & Freedom from crowding \\
19 & Comfort & Booking \\
26 & Comfort & Space and seating \\
32 & Travel time & Reasonable in-vehicle time \\
35 & Travel time & Total trip time \\
\hline
\end{tabular}

To explore the differences between how employment, age, income, and other socioeconomic variables influence the calculation results, the population was segmented using the following criteria:

- Employment status

- Household income

- Age

- Gender

- Type of municipality

- Trip purpose

- Type of obstacle

- Degree of STS use

- Use of public transport

- Degree of vehicle-pooling

The chosen segmentation of the population in the study is a com bination of standard segments and more specific ones. Starting with the tot al population results, this article discusses the following segments: age groups, employment categories, gender groups, travel purpose, number of one-way trips, mobility obstacles (e.g., wheelchair respective not wheelchair user respective), and user opinions of authority-organized vehicle pooling. 
For the statistical analysis, a logit model (Algers et al. 1987) was employed. The utility function was formulated as follows:

$$
u 1=p 10+p 11^{*} F B+p 12^{*} V V+p 13^{*} H T+p 14^{*} R T+p 15^{*} P+p 16^{*} F B E T
$$

where:

$$
\text { p10 - p16 are parameters to be estimated. }
$$

To run the estimations, the ALOGIT program (Hague Consulting Group 1992) was chosen. Based on the segmentation presented above, 29 estim ations were made.

\section{Results}

The results presented in Table 3 constitute the main findings and relationships between the variables using the full database.

\section{Table 3. Main Results of Estimated Rider Quality Variables

\begin{tabular}{|c|c|c|c|c|c|c|}
\hline \multirow{2}{*}{\multicolumn{2}{|c|}{$\frac{\text { Variable } \text { Maximum }}{\text { Waiting time at telephone }}$}} & \multicolumn{2}{|c|}{ Minimum } & \multirow{2}{*}{$\begin{array}{l}\text { Median } \\
-9.9\end{array}$} & \multicolumn{2}{|l|}{ Mean } \\
\hline & & itchboard & -24.4 & & -16.6 & -16.9 \\
\hline \multicolumn{2}{|l|}{ Frequency of service } & -29.2 & -15.2 & -20.9 & -21.1 & \\
\hline Information access & -19.9 & -6.0 & -11.3 & -11.5 & & \\
\hline Driver assistance & -7.9 & -3.0 & -5.3 & -5.5 & & \\
\hline
\end{tabular} (in minutes)}

\section{Main Results}

The maximum, minimum, median, and mean values shown in Table 3 are collected from the 29 different ALOGIT estimations. Estimates are expressed in minutes and the values are all in weight comparison to one minute in-vehicle time. 


\section{Total Population}

The nonsegmented calculation and value results for the total po pulation are shown in Table 4.

\section{Table 4. Estimation of STS Attributes for the Total Population}

\begin{tabular}{lcc}
\hline Variable & Estimate & T-value \\
\hline Waiting time at telephone switchboard & -0.6431 & $(-16.1)$ \\
Frequency of service & -0.7884 & $(-19.3)$ \\
Information access & -0.4182 & $(-10.5)$ \\
Driver assistance & -0.1666 & $(-4.2)$ \\
In-vehicle time & -0.0367 & $(-18.2)$ \\
\hline \hline Observations & 3763 & \\
Final log $(\mathrm{L})$ & -1977.8240 & \\
D,O,F, & 5 & \\
Rho $^{2}(0)$ & 0.2417 & \\
Rho $^{2}(\mathrm{c})$ & 0.2117 & \\
\hline
\end{tabular}

As shown in the table, the overall average calculation pattern is established. Note the strong $t$-values compared with the weaker $t$-value for driver assistance, which is weaker in comparison with all other selected variables in the study. On the whole, however, the chosen variables seem to be relevant to the needs of the STS pass-holder, mirrored by the random sample.

\section{Table 5. Time Valuation of STS Attributes for Total Population (in minutes)}

\begin{tabular}{lc}
\hline Variable & Minutes \\
\hline Waiting time at telephone switchboard & -17.5 \\
Frequency of service & -21.5 \\
Information access & -11.4 \\
Driver assistance & -4.5 \\
In-vehicle time & 1.0 \\
\hline
\end{tabular}


The average value path and its interrelated correlations are depicted in Table 5. Frequency of service is in the unchallenged lead. According to the total population in this study, switchboard waiting time is weighted to 81 percent, information access to 53 percent, and driver assistance to 21 percent of the weight of frequency of service. Typically in-vehicle time is far easier to tolerate when you actually are sitting in the car, compared to waiting time at telephone switchboard or frequency of service. These variables depict vital aspects on, or strong tools for, rider trip control or, in other words, our own feeling of space of action opportunities. The main problem is the lack of planning opportunities in the rider's daily life. Timetable issues are as important for this group of riders as for everybody else.

\section{Age Groups}

Waiting time at telephone switchboard was reported as the most important variable for the senior rider groups (Table 6). Waiting can be difficult even if you have free time. In this case, riders are totally bound to the call situation and their opportunities to choose between other transport modes are small compared to nonSTS pass-holders. Naturally, this is because to be a STS pass-holder normally defines a crucial mobility or economical obstacle linked to your use of buses or terminals in the public transport or regular taxi systems. For the younger rider groups, with employment or a similar day pattern, regular, survivable, repetitious weekday trips can easily be ordered in advance. In addition, to organize daily life activities inside the framework of constantly prebooked trips, is seen as a limitation to planning opportunities-a limitation on space of action in life.

\section{Table 6. Time Valuation of STS Attributes for Age Groups (in minutes)}

\begin{tabular}{lcccc}
\hline $\begin{array}{l}\text { Variable } \\
\text { Age Group }\end{array}$ & $\begin{array}{c}\mathbf{1 8 - 6 4} \\
\text { Minutes }\end{array}$ & $\begin{array}{c}\mathbf{6 5 - 8 4} \\
\text { Minutes }\end{array}$ & $\begin{array}{c}>65 \\
\text { Minutes }\end{array}$ & $\begin{array}{c}<=64 \\
\text { Minutes }\end{array}$ \\
\hline Waiting time at telephone switchboard & -15.2 & -17.6 & -18.5 & -15.9 \\
Frequency of service & -21.6 & -20.0 & -20.8 & -22.5 \\
Information access & -10.2 & -11.2 & -11.3 & -11.6 \\
Driver assistance & $*$ & -4.7 & -5.6 & $*$ \\
In-vehicle time & 1.0 & 1.0 & 1.0 & 1.0 \\
\hline
\end{tabular}

*Not significant at 95 percent level 
Not surprisingly, frequency of service is valued highest in the younger group and driver assistance in the oldest rider group. But the frequency of service value only occupies rank seven in the total list; that is, six other segme nts put more weight on frequency of service. For driver assistance, there is a distinct valuation difference between the limit group 65-84 and the unlimited group $>65$.

\section{Employment Categories}

In the employed STS pass-holder group, lower values connected with waiting time at telephone switchboard, frequency of service, and information access were observed compared to the population as a whole (Table 7). Information access is not an important point here in relation to the other variables, probably because of a frequent use of the STS system.

\section{Table 7. Time Valuation of STS Attributes for Employed/Student Respective Not Employed/Student (in minutes)}

\begin{tabular}{lcc}
\hline Variable & $\begin{array}{c}\text { Employed/Student } \\
\text { Minutes }\end{array}$ & $\begin{array}{c}\text { Not Employed/Student } \\
\text { Minutes }\end{array}$ \\
\hline Waiting time at telephone switchboard & -14.4 & -18.1 \\
Frequency of service & -16.0 & -22.4 \\
Information access & -6.0 & -12.3 \\
Driver assistance & $*$ & -4.9 \\
In-vehicle time & 1.0 & 1.0 \\
\hline
\end{tabular}

*Not significant at 95 percent level

On the other hand, all of the variables in the nonemployed ride $r$ group have increased weights, with the same starting point for comparison. As discussed in the age group section above, these facts can be seen in the lig ht of differences in the demands of daily life. An employed person has more nonnegot iable, timefixed tasks and meetings to confront.

\section{Gender Groups}

As shown in Table 8, the ranking order is the same between the sexes. Note the high weight for frequency of service and its relation in minute s to in-vehicle time reported by male STS pass-holders. In comparison with the total population re- 
sults, men are consistently making a higher attribute valuation. In other words, men are more demanding about the STS service standards identified in this study. The female value for waiting time at telephone switchboard is only 75 percent of the male value. In this study, typical

STS pass-holders are women. As stated earlier, the usual STS pass-holder is a woman with pension benefits; the most frequent STS user is, in contra st, an employed younger man.

\section{Table 8. Time Valuation of STS Attributes for Gender Groups (in minutes)}

\begin{tabular}{lccc}
\hline Variable & $\begin{array}{c}\text { Men } \\
\text { Minutes }\end{array}$ & $\begin{array}{c}\text { Women } \\
\text { Minutes }\end{array}$ & $\begin{array}{c}\text { Difference } \\
\text { Minutes }\end{array}$ \\
\hline Waiting time at telephone switchboard & -21.2 & -15.9 & -5.3 \\
Frequency of service & -23.5 & -20.2 & -3.3 \\
Information access & -12.9 & -10.8 & -2.1 \\
Driver assistance & -7.4 & -3.0 & -4.4 \\
In-vehicle time & 1.0 & 1.0 & 0.0 \\
\hline
\end{tabular}

\section{Travel Purpose}

This study looked at three types of travel purposes: work trips, visiting trips, and hospital trips (Table 9).

\section{Table 9. Time Valuation of STS Attributes for Travel Purpose (in minutes)}

\begin{tabular}{lccc}
\hline Variable & $\begin{array}{c}\text { Work Trip } \\
\text { Minutes }\end{array}$ & $\begin{array}{c}\text { Visiting Trip } \\
\text { Minutes }\end{array}$ & $\begin{array}{c}\text { Hospital Trip } \\
\text { Minutes }\end{array}$ \\
\hline Waiting time at telephone switchboard & -14.6 & -14.6 & -20.4 \\
Frequency of service & -20.1 & -18.5 & -24.2 \\
Information access & -10 & -9.9 & -12.6 \\
Driver assistance & $*$ & $*$ & -6.1 \\
In-vehicle time & 1.0 & 1.0 & 1.0 \\
\hline
\end{tabular}

*Not significant at 95 percent level 
Waiting time at telephone switchboard to order work trips can, by planning activities in advance, be reduced in respect to frequency and therefore is not as highly valued as we would expect. In the work-trip case, the value of information access about vehicle pooling is slightly lower than for the tot al population. Riders ordering visiting trips are typically more patient regarding punctuality of departure or arrival precision.

On the other hand, hospital trips demand a quick response from the telephone switchboard: Users needing hospital treatment typically require a rapid one-way ride. This trip category is clearly on top in all values when comparing the values of total population.

In frequency of service, the valuation differences between the different travel types are what we can expect. For hospital trips, the valuation of frequency of service is the second highest value in the study. Only wheelchair riders place a higher value on frequency of ride.

The values in Table 9 indicate that if the authorities need to cut STS costs, they should not do it in waiting time at telephone switchboard or frequency of service qualities. Costs should be cut by extending the in-vehicle time, that is, when the user is finally riding in the vehicle. Total trip time, the total time span from ordering a ride to the actual arrival at the agreed destination, is another quality aspect not to be forgotten, but not calculated in this study.

\section{Number of One-Way Trips}

Note the value levels of the seldom/never rider fraction in Table 10. The value for waiting time at telephone switchboard is 17 percent higher, frequency of service

\section{Table 10. Time Valuation of STS Attributes for Number of One-Way Trips (in minutes)}

\begin{tabular}{lccc}
\hline Attribute & $\begin{array}{c}\text { Daily/Weekly } \\
\text { Minutes }\end{array}$ & $\begin{array}{c}\text { EveryMonth } \\
\text { Minutes }\end{array}$ & $\begin{array}{c}\text { Seldom/Never } \\
\text { Minutes }\end{array}$ \\
\hline Waiting time at telephone switchboard & -15.3 & -14.8 & -20.5 \\
Frequency of service & -22.1 & -21.3 & -20.4 \\
Information access & -10.8 & -9.2 & -12.5 \\
Driver assistance & -4.9 & -6.1 & $*$ \\
In-vehicle time & 1.0 & 1.0 & 1.0 \\
\hline
\end{tabular}

*Not significant at 95 percent level 
5 percent lower, and information access 10 percent higher than in the total population calculation. These values imply that STS pass-holders wh o travel rather seldom need to have a relatively higher transportation quality than the more frequent and experienced STS users.

\section{Mobility Obstacles: Wheelchair User Respective Not Wheelchair User}

STS technical performance differs between wheelchair riders and other STS passholders in reference to vehicle demands (Table 11). Usually, wheelchair users need minivan transport as opposed to basic taxicabs.

\section{Table 11. Time Valuation of STS Attributes for Mobility Obstacles: Wheelchair User Respective Not Wheelchair User (in minutes)}

\begin{tabular}{lcc}
\hline Variable & $\begin{array}{c}\text { Wheelchair } \\
\text { Minutes }\end{array}$ & $\begin{array}{c}\text { Not Wheelchair } \\
\text { Minutes }\end{array}$ \\
\hline Waiting time at telephone switchboard & -18.5 & -17.6 \\
Frequency of service & -29.2 & -20.6 \\
Information access & -13.6 & -11.3 \\
Driver assistance & $*$ & -5.0 \\
In-vehicle time & 1.0 & 1.0 \\
\hline
\end{tabular}

*Not significant at 95 percent level

Compared to the total population figures, Table 12 shows that the deviations expressed in percent are obvious. All statistically significant variables are increased in the wheelchair user group, especially the levels of frequency of service respective and information access. Wheelchair users must plan ahead, down to the smallest details.

Here again, this situation brings up the discussion of personal alternative costs in all respects. 


\section{Table 12. Comparison between Wheelchair User Respective Not Wheel- chair User and Total Population Values (in percent)}

\begin{tabular}{lcc}
\hline Variable & Wheelchair & $\begin{array}{c}\text { Not } \\
\text { Wheelchair }\end{array}$ \\
\hline Waiting time at telephone switchboard & 106 & 101 \\
Frequency of service & 136 & 96 \\
Information access & 119 & 99 \\
Driver assistance & $*$ & 111 \\
In-vehicle time & 100 & 100 \\
\hline
\end{tabular}

*Not significant at 95 percent level

\section{User Opinions of Authority-Organized Vehicle Pooling}

As stated in the introduction, vehicle pooling is the basic quality standard of today's STS performance. Vehicle pooling consists of a large number of IQR attributes. Sharing passenger seats in an STS vehicle is, in many ways, like sharing passenger seats in the regular public transport buses. In the STS case, though, negative qualities are added (e.g., rider uncertainty about rou te orientation and timetable issues). Imbedded in the authority-organized vehicle-pooling situation is an indefinite loss of space of action, daily life overview, and opportunities for planning ahead. These losses need to be seen from a very long-term, never-ending, and repetitious perspective as opposed to one or two occasions weekly.

Table 13. Time Valuation of STS Attributes for Positive, Respective, Negative Opinion of Authority-Organized Vehicle Pooling (in minutes)

\begin{tabular}{lcccc}
\hline Variable & $\boldsymbol{A}$ & $\boldsymbol{B}$ & $\boldsymbol{C}$ & $\boldsymbol{D}$ \\
& Minutes & Minutes & $\begin{array}{c}\text { Minutes } \\
\text { Minutes }\end{array}$ \\
\hline Waiting time at telephone switchboard & -18.2 & -17.2 & -13.2 & -9.9 \\
Frequency of service & -20.8 & -19.0 & -15.2 & -23.2 \\
Information access & -8.5 & -9.3 & -11.4 & -15.5 \\
Driver assistance & $*$ & -3.7 & -7.9 & $*$ \\
In-vehicle time & 1.0 & 1.0 & 1.0 & 1.0 \\
\hline
\end{tabular}

*Not significant at 95 percent level 
Legend:

$A=$ Indeed positive to vehicle pooling.

$\mathrm{B}=$ Rather positive to vehicle pooling.

$C=$ Rather negative to vehicle pooling.

$\mathrm{D}=$ Indeed negative to vehicle pooling.

Table 13 shows the great value span in the variable values for the indeed negative users. The indeed negative riders to vehicle pooling have the most striking deviations in valuation compared to the total population. That is, waiting time at telephone switchboard is valued at 57 percent - lowest of all segments-frequency of service to 108 percent, and information access to 136 percent of the total population weights.

The rather negative STS pass-holders value frequency of service lowest of all segments and driver assistance highest of all 15 statistically sig nificant segments in the study.

Positive riders, in contrast, are on the whole rather close to the total population values. The valuation of information access is, not surprisingly, lower in the positive segments in comparison with the total population pattern. In relation to information access, the other variable values in these groups a re strongly increasing. They are placed in the quality forefront.

Another observation to take into account concerns driver assist ance. The rather positive riders value this variable to less than half, or 3.7 m inutes, compared with the rather negative STS pass-holders value of 7.9 minutes. The total population value for this variable is 4.5 minutes.

These facts point out the importance of not viewing the collective of STS passholders as a homogeneous group of transport consumers who react in the same manner to STS mode design and performance changes. 


\section{Discussion}

An important political policy shift has taken place in the STS from the social policy area to the transport domicile. This trend is supported by the Swedish Special Transport Service Act 1997 (SFS 1997:736). Since 1998, STS has been seen as an integrated part of the public transport system in Sweden. The explicit authority intention was, and still is, to reduce government spending and make the STS transport system more cost effective from the organizers' perspective. The transportation authority also aimed to stimulate an overflow of pass engers from the expensive STS transport system to the cheaper regular public transport bus system.

Several STS issues are of vital interest from a regional planni ng perspective. The STS service has experienced a reduction in performance. In 2001, the STS served 400,200 pass-holders, or 4.5 percent of the Swedish population. In 1994, 441,300 passholders were accommodated. The total number of STS trips has be en reduced from 17.5 million one-way trips in 1994 to 13.6 million in 2001 . Government costs in 2001 were roughly 2 billion Swedish kronor, or \$ U.S. 215 million.

The authority-organized vehicle-pooling technique is successful from the organizers' perspective because the vehicles are filled by picking up passengers in the district or during the trip in the direction of the destination.

Based on this information, a Swedish methodology for calculatin g rider quality in STS was developed. The methodology uses utility modelling prese nted in a Swedish context for the first time in 1998 (Knutsson 1998, 2000). The model used is based on the basic logit formulation and estimated with the ALO GIT program.

Estimated rider quality variables are shown in Table 3.

Table 14 shows the valuation of the rather or indeed negative to authority-organized vehicle-pooling STS pass-holders. To extend the in-vehicle time, in contrast maybe to the not here valued total trip time, is the least expe nsive change. The subject for quality standard comparison is the timetable in the regular public bus system in contrast to taxis. Another area to address involves prolonging the wait time at telephone switchboard. One way to present these suggest ions is through strengthened user information access. 


\section{Table 14. Comparison between Rather Respective Indeed Negative Opinion of Authority-Organized Vehicle Pooling (in minutes)}

\begin{tabular}{lcc}
\hline Variable & $\begin{array}{c}\text { Rather } \\
\text { Minutes }\end{array}$ & $\begin{array}{c}\text { Indeed } \\
\text { Minutes }\end{array}$ \\
\hline Waiting time at telephone switchboard & -13.2 & -9.9 \\
Frequency of service & -15.2 & -23.2 \\
Information access & -11.4 & -15.5 \\
Driver assistance & -7.9 & $*$ \\
In-vehicle time & 1.0 & 1.0 \\
\hline
\end{tabular}

From the passenger perspective, however, these proposals are a further cut into the space of action and daily life planning opportunities.

For wheelchair users, one of the most vulnerable rider groups, frequency of service ranks as the top quality priority. To thin out frequency of service beyond the public transport bus standard in the region to fill up the vehicles, is an expensive alternative.

In seeking the best alternatives, the organizers want to mainta in good relations, confidence, and goodwill with STS pass-holders and at the same time, diminish customer complaints. Their aim is comfortable travel for all.

The rider quality index (IRQ) and the Swedish results can contribute constructively toward a focused, decisive quality development within the regular public transportation system from a city perspective. If we are to succeed in this endeavor, a public transportation standard must be offered that, at the very least, corresponds to the demands and needs of both employed and elderly disabled riders.

\section{Acknowledgment}

The author wishes to thank Dr. Jonas Elisasson, Transek AB, Solna, for his contribution regarding the statistic estimations done on the survey material; and $\mathrm{Dr}$ Karl Kottenhoff, Department of Infrastructure, Royal Institute of Technology, Stockholm, for the stated preference method advice regarding the questionnaires used in this study. 


\section{References}

Algers, S., et al. 1987. The logit model: Usefulness and generalisability. Rapport R30. Stockholm: Swedish Council for Build Research.

Gillingwater, D., et al. 1995. Community transport: Policy, planning, practice. Transportation Studies 15.

Hague Consulting Group. 1992. ALOGIT UsersGuide Version 3.2.

Jones, P. 1989. An overview of stated preference techniques. P.T.R.C course lecture notes, Oxford University Transport Studies Unit, Oxford.

Knutsson, S. 1998. Valuing rider quality in Special Transport Services. TRITA-IP FR 98-43, Department of Regional Planning, Royal Institute of Technology.

Knutsson, S. 1999. The goals of Special Transport Services production. A comparison between Stockholm County, Gothenburg City and Östergötland County. Stockholm: KFB-Meddelande.

Knutsson, S. 2000. To value Special Transport Services with the Index of Rider Qua Iity. TRITA-IP FR 00-73, Department of Regional Planning, Royal Institute of Technology.

McKee, C. 1993. Rail vehicles accessible to disabled passengers. Proceedings of Seminar J held at the PTRC European Transport, Highways and Planning $21^{\text {st }}$ Summer Annual Meeting 1993, UMIST, Vol. P371.

McKnight, C. E. et al. 1986. Using quality to predict demand for special transportation. Behavioural Research for Transport Policy. Utrecht: VNU Science Press, 423-441.

National Board of Health and Welfare. 1998. Special Transport Services statistics 1997.

Stockholm: Satistik Socialtjänst.

Paaswell, R. E. 1977. Estimation of demand for transit service among the transportation disadvantaged. Transportation Research Record 660: 38-49.

Pearmain, D. et al. 1991. Stated preference techniques: a guide to practice. Steer Davies Gleave. Hague Consulting Group uo 1991, 2 uppl.

SFS 1997:734. Specialised public transport responsibility Act. 
SFS 1997:736. Swedish Special Transport Service Act 1997.

SIKA. 2002. Special transport services and national special transport services 2001. Stockholm: Institutet för kommunikationsanalys.

Sutton, J. 1990. Travel choice and mobility handicapped: Some preliminary investigations utilising a disaggregated choice model. Transportation Planning and Technology 14: 229-241.

Thatcher, R. H., et al. 1991. ADA paratransit handbook: Implementing the complementary paratransit service requirements of the Americans with Disabilities Act of 1990. Washington DC: UMTA.

Widlert, S. 1992. Stated preferences: A method to estimate values and behaviour. Stockholm: Department of Traffic Planning, Royal Institute of Technology and Transek AB.

\section{About the Author}

Stig Knutsson (stig.knutsson@socarb.su.se) holds a Ph.D. from the Department of Infrastructure and Planning at the Royal Institute of Technology in Stockholm. His research interests deal with special transport services, rider quality, combined transport, and urban and regional planning. He is also interest ed in welfare, housing, and home systems for elderly and disabled residents. Dr. Knutsson worked 15 years as head of a community social services department in Dala rna County and is now senior lecturer in the Department of Social Work, Stockholm University. 